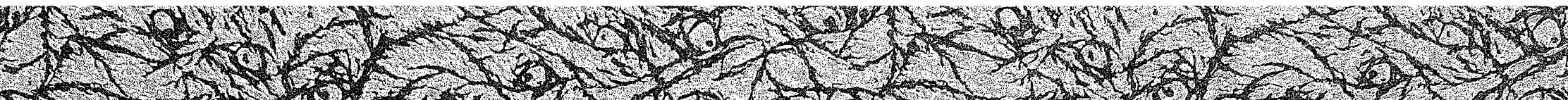

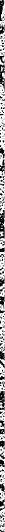

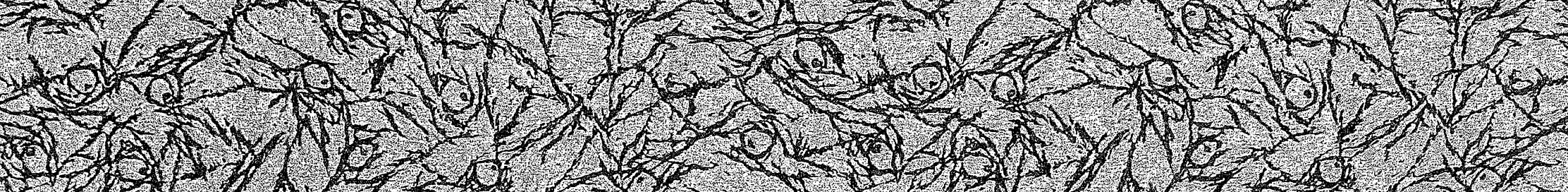

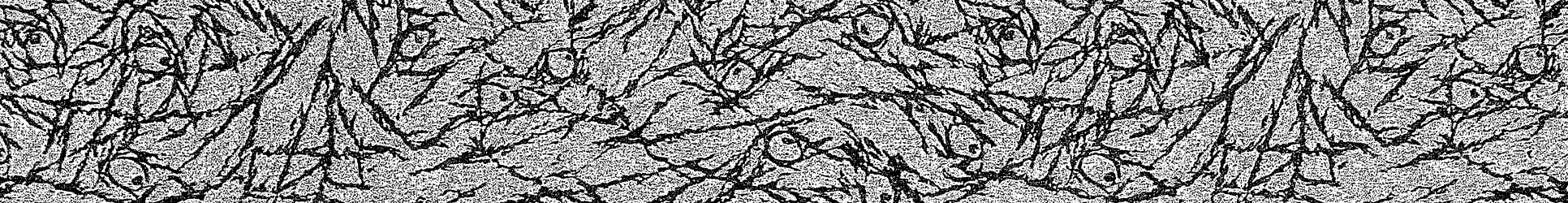

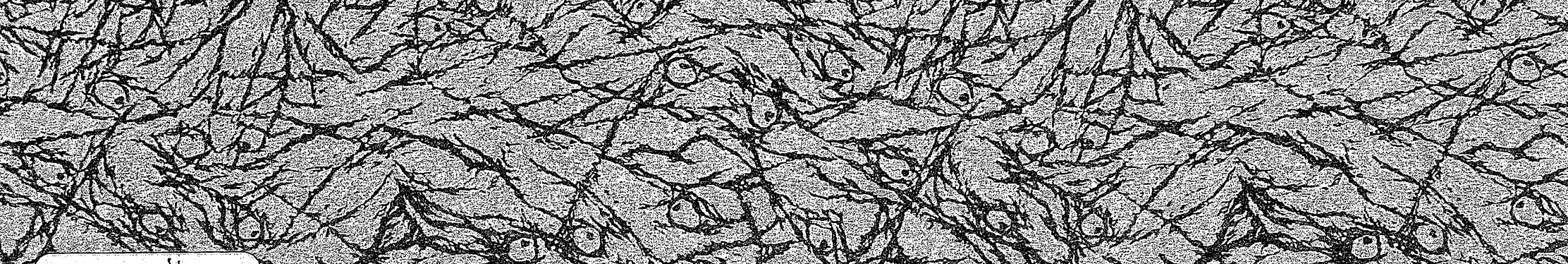

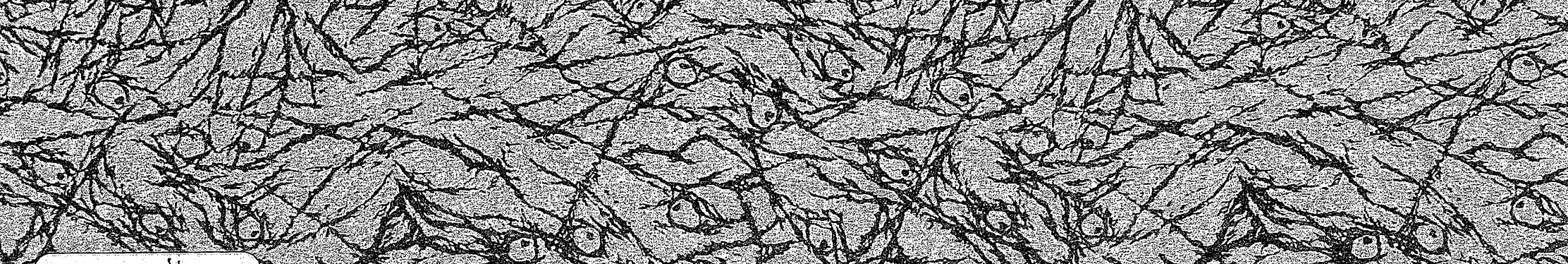

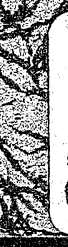

翼暴号

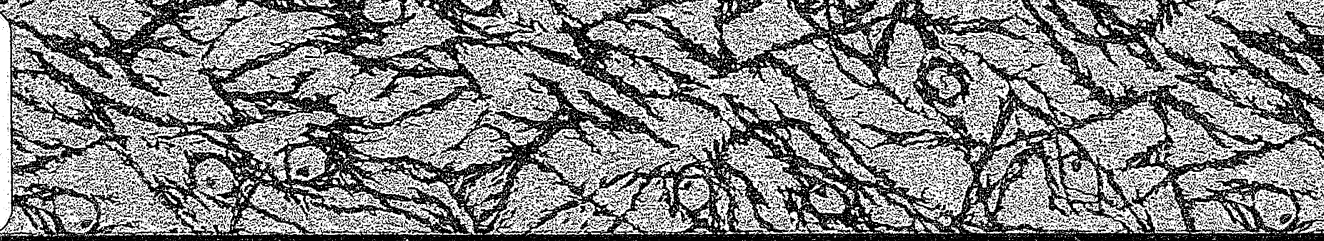



$\neq$

16 


\title{
\begin{tabular}{llllllll}
$\mathbf{B}$ & $\mathbf{e}$ & $\mathbf{r}$ & $\mathbf{i}$ & $\mathbf{c}$ & $\mathbf{h}$ & $\mathbf{t}$ & $\mathbf{e}$ \\
\hline
\end{tabular}
}

\section{Measuring the Effects of German Budget Policies, $1955-65$}

\author{
By \\ Wayne W. Snyder
}

Contents: I. The Measurement of Budget Effects. - II. The Effects of Budget Changes in Germany, 1955-65. - III. Evaluating Economic Stability and Balanced Growth. - IV. Summary and Conclusion. - V. Appendix.

The purpose of this study is to measure the effects of various types of budget changes and evaluate their impact on the achievement of economic stability and balanced growth during the eleven year period from igs 5 through 1965. The basic data and methods used to estimate the effects of budget changes are the same as those developed by Bent Hansen ${ }^{1}$ for a recent OECD survey which gives the institutional background to budgetary action and an analysis of the nature and effects of fiscal policy for each of seven member countries: Belgium, France, Germany, Italy, Sweden, the United Kingdom and the United States.

The Hansen study provided three measures to characterize the impact of budget changes: the average annual effect on domestic demand, the effect on the slope of this trend, and the short-term dampening effect on potential fluctuations in the actual GNP-growth rate. The study did not attempt to weigh these three factors together in order to evaluate their combined effect on achieving economic stability and balanced growth. Partly, this was because there were no officially recognized criteria of what level of demand would have been appropriate for each of the seven countries.

Remark: I am particularly indebted to J. C. R. Dow who conceived and directed the OECD study of fiscal policy, and to Bent Hansen with whom I had the pleasure of working for two years completing it. I am also grateful for the helpful editorial assistance of Janet Eckstein.

${ }^{1}$ Bent Hansen Assisted by Wayne W. Snyder, Fiscal Policy in Seven Countries, 1955-1965, Belgium, France, Germany, Italy, Sweden, United Kingdom, United States, OECD Publications, No. 24,023, Paris, 1969. 
This paper supplements the Hansen study for Germany by providing more disaggregated data about the relative importance of various types of budget changes, and by assessing the degree to which their overall impact enhanced the achievement of a high level of economic stability and growth during the late I950's and early I960's. The latter requires using estimates of potential output, even though it is recognized that these are neither unique nor unambiguous, because they require assumptions about the rate of growth of the labor force and its productivity which are influenced by government policies affecting the distribution of output between consumption and investment. In spite of this limitation they provide a useful point of departure for evaluating budgetary performance and for discussing other major economic objectives, e.g., relative price stability and balance of payments equilibrium.

Germany in 1955 was in several ways at a rather different stage of its economic development from some of the other countries in the Hansen study, although in other respects its range of economic problems was not so very dissimilar. In the years immediately following World War II, unemployment in Germany was higher than in any other European country, except Italy, but by 1955 Germany was rapidly becoming a fully employed economy ${ }^{1}$. Several other European countries, e. g., France, the Netherlands, Sweden, and the United Kingdom, already had achieved the full employment of their human resources before 1950, and from that time onward their major concern was to maintain a balanced economy which required, on the one hand, avoiding a level of demand requiring over employment and the imbalances caused by an inflationary situation and, on the other hand, an undesirably high level of unemployment. Germany did not permanently enter this phase of its development until 1959, although its fullemployment potential output was virtually attained during 1956 and 1957 before the slow down during the brief and not too severe world-wide recession of 1958 occurred. Belgium and Italy, however, still had substantial unemployment in 1959 , and it was not until nearly a decade later that these two countries began to face the delicate problem of managing their economies so as to achieve simultaneously full employment and economic stability - a problem already faced by some European countries for over fifteen years. The United States presents a rather different and peculiar case. It had maintained a reasonably high level of employment fairly continuously after the end of World War II, except for two sharp but shortlived recessions, but after ro5s economic policies allowed unemployment to become increasingly serious until a number of very important special measures were taken in $1964-65$ which helped to regain full employment.

Germany, then, presents the interesting case of an economy approaching what has been called the era of fine economic tuning where policies are

${ }^{1}$ See Angus Maddison, Economic Growth in the West, Comparative Experience in Europe and North America, A Twentieth Century Fund Study, London, 1964, for a general description of the various economic situations and problems among Western countries in the postwar period up to I 960 , especially Appendix E for details about unemployment. 
required to be varied within a "narrow band"1 in order to avoid either the inflationary pressures of excessive demand, or the under employment of an economy's full potential. Given the above brief description of the German economy, one should expect around the end of the I950's a switch from generally expansive budget policies designed to achieve full employment to more flexible ones adopted to meet the challenge of full employment. German budget policies during the years from I95s through 1965 were, however, very little influenced by conjunctural considerations, and were primarily based on the philosophy that budgets should be balanced in order to achieve financial responsibility which accompanied by the automatic responses of the private sector would assure the best functioning of the economy. As suggested in an OECD expert report on fiscal policy "Germany was the last of the seven countries to resort to budget policy as a means of managing demand"2. The estimates of the budget effects and their impact on economic stability and balanced growth must, then, be viewed as the implicit results of a general economic policy of nonintervention.

\section{The Measurement of Budget Effects ${ }^{3}$}

To determine the effect of the budget we must first estimate what would have occurred if there had been no change in the budget, i. e., if all expenditures and all revenues had remained constant from one period to the next. The difference between this estimate and the actual development can be attributed to a budget effect. When government expenditures and revenues change, the effect occurs in a several stage process. First, there is the direct impact of the increased (or decreased) spending occasioned by the initial budget change. The initial change induces a series of indirect (multiplier) effects. The combination of all the direct and indirect effects, or the "total effects" of budget changes, are traditionally classified in two types: discretionary and automatic, built-in stabilizers ${ }^{4}$. This distinction is necessary for a discussion of budgetary policies because it divorces those effects which are due to specific new government actions from the effects which

1 Organization for Economic Co-operation and Development, Fiscal Policy for a Balanced Economy, Experience Problems and Prospects, OECD Publications, No. 24,827, Paris, 1968, p. 16.

2 Ibid., p. 24 .

- A more detailed explanation of the measurement methods is given in the Appendix. For a complete description of the methods used see Hansen, op. cit., Chapter I.

- In general, the total effects of budget changes on domestic demand should also include the feed-back or "accelerator effects" which account for the impact that budget changes have on private investment when demand is altered by the initial budget change (and in turn the additional household demand that this affects too). As will be explained later, however, the actual model used assumed that all changes in private investment were exogenously determined; hence the measurement of budget effects is limited in this respect as well as by the others described further on. 
are produced by existing laws and regulations; the difference between the two categories, however, is by no means unambiguous.

When changes in budget expenditures or revenues are clearly due to deliberate and explicit measures that are unrelated to previous legislation or budget authorizations, then it is certainly appropriate to classify them as discretionary. For example, the dampening effect caused by the increased revenue derived from a new tax law or that part due to a change in the tax rate can be called discretionary. While national accounts data do not breakdown total tax receipts between discretionary and automatic, the two parts can be separately estimated. For Germany, estimates of the change in tax revenue due to discretionary measures were based on information supplied by and consultation with the Ministry of Finance for the Bund as well as for the Länder and Gemeinden. Unfortunately, however, the breakdown between discretionary and automatic changes could not be made for the years 1955- 57 . This study assumes that all changes in expenditures (except social security) are discretionary. Strictly speaking this assumption can be justified, because most annual expenditures require new budget authorizations. But the true discretionary element may be substantially less, because many categories of expenditures cannot be varied easily and not all expenditures require new approval. For example, expenditures for education are often related to the size and composition of a growing population which is a built-in factor setting a minimum annual increase, and payments in agricultural subsidy programs are not always subject to new annual appropriations. Even changes in tax rates are sometimes legislated to occur at future dates, which makes it ambiguous whether to call their effects discretionary or automatic when they eventually occur.

It is conventional to define as automatic effects the changes of tax receipts and expenditures that occur under existing laws. In the absence of new taxes or rates, all changes in tax revenues are automatic and are caused by variations in private income and expenditures. The most important automatic changes in expenditures occur in the social security programs: health, pension, and unemployment benefits. Estimates of the discretionary changes in both contributions and benefits of the social security programs were based on information supplied by and consultations with the Ministry of Labor and Social Affairs, and these are available for each year from ross through 1965 .

One final explanation is necessary. The measures of the effects of budget changes purport to estimate the impact on domestic demand. This required obtaining special information about government civil imports and the amount of military purchases abroad in order to adjust gross government expenditures to obtain their impact on domestic demand only. Because year-to-year variations in military payments abroad were especially important, and because some uncertainty remains about how they were treated in the national account statistics, some not inconsiderable measurement errors may remain with respect to the impact of government purchases of goods and services for some years but certainly not all. 
Table I - Annual Effects of Budget Changes

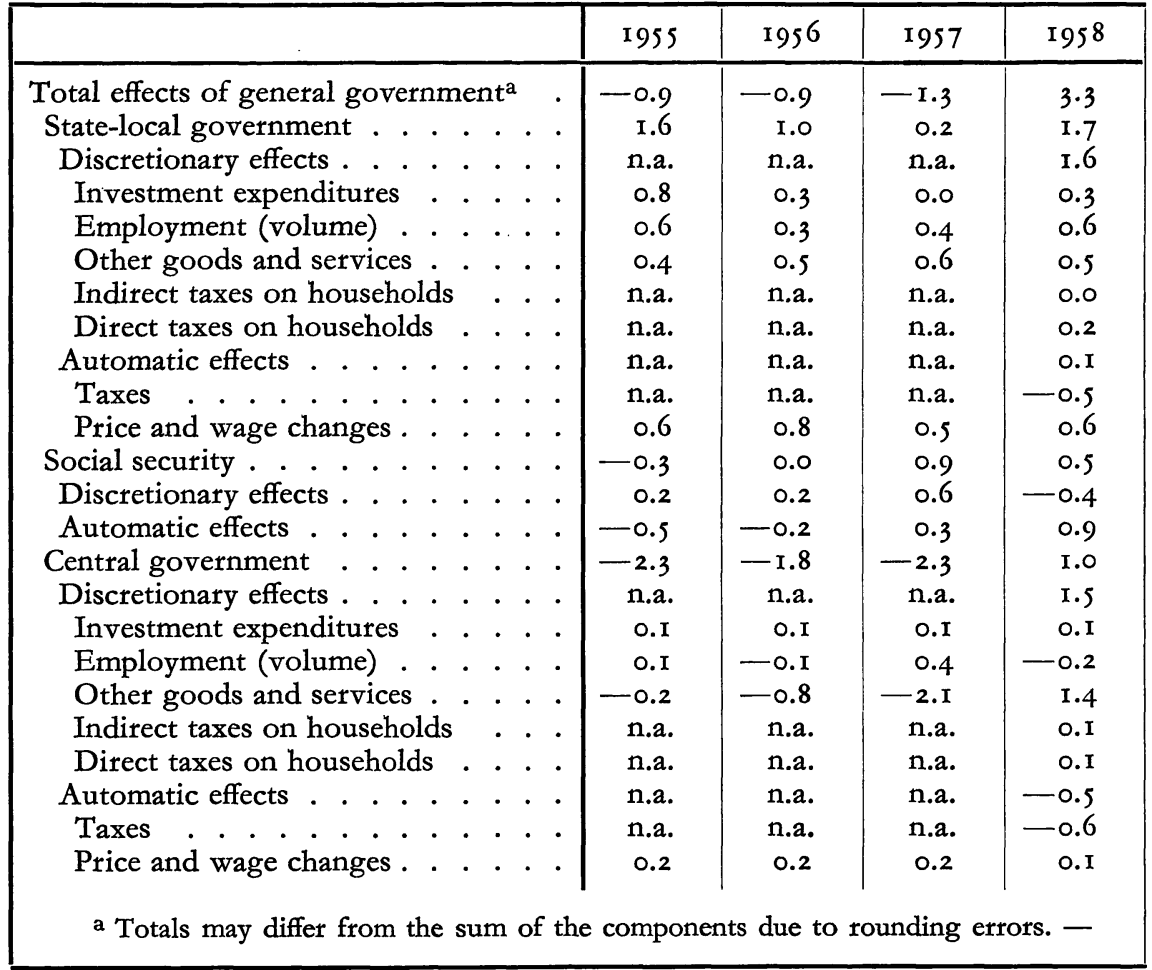

\section{The Effects of Budget Changes in Germany, 1955-65}

Estimates of the total effects of annual budget changes, expressed as a percentage of the previous year's GNP, and a breakdown of the effects into discretionary and automatic for various categories of government expenditures and receipts are given in Table $\mathrm{I}$. The first and most important conclusion to draw from these estimates is that the typical impact of general government - the combined effect of Bund, Länder, Gemeinden, and social security - amounted to about I per cent of GNP, although in two years the effect exceeded 2 per cent. When it is remembered that the average annual change in GNP amounted to 6.I per cent during the period from I955 to 1965 - the highest among the seven countries in the Hansen study it is evident that budget changes did little to alter the course of economic change. Second, the budget impact as often dampened domestic demand as contributed to it, although on balance the budget changes accounted for an average positive push of 0.4 per cent of GNP. This was not, however, distributed equally throughout the period. From 1955 through 1959, at 
Measuring the Effects of German Budget Policies, r955-65

as Percentage of $G N P_{\mathrm{t}-1}, 1955-65$

\begin{tabular}{|c|c|c|c|c|c|c|c|}
\hline 1959 & $1960^{b}$ & $196 \mathrm{r}$ & 1962 & 1963 & 1964 & 1965 & Average \\
\hline-0.7 & -I.O & 0.3 & I.8 & 1.3 & -0.2 & 2.4 & 0.4 \\
\hline -O.I & O.I & 0.1 & I. 7 & I.8 & I.3 & I.9 & 0.9 \\
\hline I. 4 & I. 4 & I.0 & I.9 & I. 4 & 1.6 & I. 4 & $1.6^{c}$ \\
\hline 0.7 & 0.4 & 0.4 & 0.8 & 0.6 & 1.0 & 0.2 & 0.5 \\
\hline 0.3 & 0.3 & 0.2 & 0.4 & 0.4 & 0.3 & 0.4 & 0.4 \\
\hline 0.3 & 0.5 & 0.3 & 0.5 & 0.4 & 0.3 & 0.5 & 0.4 \\
\hline 0.0 & 0.0 & 0.0 & 0.0 & 0.0 & 0.0 & 0.0 & $0.0^{c}$ \\
\hline O.I & 0.2 & 0.1 & 0.2 & 0.0 & 0.0 & 0.3 & $0 . \mathrm{I}^{\mathrm{c}}$ \\
\hline-1.5 & -1.3 & -0.9 & -0.2 & 0.4 & -0.3 & 0.5 & $-0.4^{c}$ \\
\hline-1.7 & -2.0 & -1.9 & - I.0 & -0.2 & -I.I & -0.5 & $-\mathrm{I} . \mathrm{I}^{\mathrm{c}}$ \\
\hline 0.2 & 0.7 & I.0 & 0.8 & 0.6 & 0.8 & I.O & 0.7 \\
\hline-0.1 & -0.8 & 0.2 & $0 . \mathrm{I}$ & 0.2 & $0 . \mathrm{I}$ & -0.2 & 0.1 \\
\hline o.r & 0.0 & 0.2 & 0.2 & $0 . \mathrm{I}$ & 0.5 & 0.0 & 0.2 \\
\hline-0.2 & -0.8 & 0.0 & -0.1 & 0.1 & -0.4 & -0.2 & $-0 . I$ \\
\hline - I.4 & -0.4 & 0.0 & O.I & -0.6 & -1.6 & 0.7 & -0.8 \\
\hline 0.5 & I.I & I.7 & I. 5 & 0.5 & -0.6 & I. 3 & $0.9^{\mathrm{c}}$ \\
\hline 0.3 & 0.1 & 0.1 & 0.2 & $0 . \mathrm{I}$ & 0.0 & 0.1 & $0 . \mathrm{I}$ \\
\hline 0.0 & 0.2 & 0.3 & 0.3 & 0.2 & $0 . \mathrm{I}$ & 0.1 & $0 . \mathrm{I}$ \\
\hline 0.2 & 0.9 & I. 2 & 0.9 & 0.2 & -0.6 & 0.9 & 0.2 \\
\hline 0.0 & -0.2 & 0.1 & 0.0 & 0.0 & -0.1 & 0.0 & $0.0^{c}$ \\
\hline 0.0 & O.I & 0.0 & $0 . \mathrm{I}$ & 0.0 & 0.0 & 0.2 & $0 . \mathrm{I}^{\mathrm{c}}$ \\
\hline-1.9 & - 1.5 & $-\mathrm{r} .7$ & -I.4 & 一I.I & $-\mathrm{I} .0$ & -0.6 & $-\mathrm{I} .2^{\mathrm{C}}$ \\
\hline-2.0 & $-\mathrm{I} .8$ & -2.0 & -1.6 & $-\mathrm{I} \cdot 3$ & -1.3 & -0.9 & $-\mathrm{I} .4^{\mathrm{c}}$ \\
\hline O.I & 0.3 & 0.3 & 0.2 & 0.2 & 0.3 & 0.3 & 0.2 \\
\hline
\end{tabular}

a time when the economy generally tended to function below its full potential, the budget impact on average was virtually nil whereas from 1960 to 1965 , when full or overfull employment prevailed, the budget added about 0.8 per cent to the GNP-growth rate, creating a tendency towards the inflationary situation which is discussed later in this study.

The state-local sector (i. e., Länder and Gemeinden) is the largest of any country in the world. This partly explains why its impact was substantial, and on average added 0.9 per cent to the GNP-growth rate. This resulted from the generally steady growth of all categories of expenditures - investment, employment, and the purchase of other goods and services - accompanied by the regular positive push from the effect of price and wage increases. Discretionary changes in taxes did little to alter the course of events, although the effect of frequently lowering income tax rates on households did provide a small upward impact in most years. The automatic increases in taxes - direct and indirect combined - due to rising income and expenditures put a large "fiscal drag" on what otherwise would have been a much 
larger expansionary effect of the state-local sector; these were noticeably anti-cyclical, the downward effect being much reduced in the recession year 1958 as compared with the large dampening impact registered in the years when GNP increased the most, 1959-60. The combined or total effects of the state-local government sector did vary some from year-to-year, and its impact was generally more expansive after 1961 than in the preceding years.

The central government sector, considered alone, generated a dampening effect which averaged -0.8 per cent of GNP. This contractionary impact is somewhat misleading, however, because it does not take into account the increasingly large annual transfers to state-local government and the even more important ones provided to the social security system. The impact of these has been included in whichever sector their ultimate use actually occurred, but if they had been included as part of the effects of central government, the generally negative impact of its budget changes would have been substantially reduced (with a corresponding reduction in the positive effects of the state-local government and the social security system). Nevertheless, the combined impact of changes in the budget by the central government would remain a dampening influence because large overall surpluses occurred throughout most of the period, and they were especially large during the years prior to 1958 when the "Julius Tower" was being accumulated $\mathbf{1}$.

Two general aspects of impact of central government budget changes need to be discussed. First, the average contractionary force in the years 1955-59 was considerably stronger than afterwards, - -4 per cent of GNP as compared with -0.4 per cent. It is impossible to fully discuss variations during the entire period for the various types of budget changes because information is lacking about the size of discretionary changes in taxes during the years $1955-57$. Nevertheless it is possible to indicate the major sources of change during the decade. Defense expenditures - employing armed forces personnel and the domestic purchases of goods and services connected with the military build-up - increased substantially from 1958 with the advent of the NATO rearmament program; whereas the discretionary impact of both current and capital expenditures had been negative from 1955 through 1957, afterward it became a positive factor in every year except 1964. Important tax reductions occurred in 1954, but no estimates of their impact are available; those that are available for the years afterward indicated that changes in indirect and direct taxes played only a very minor role in the course of economic development. On the other hand, automatic increases in tax revenue acted as a dampening force for the central government as it did for the state-local sector. Second, although the state-local government is substantially larger than the central

${ }^{1}$ See Hansen (op. cit., pp. 240 sq.) for a discussion of the philosophy and significance of the accumulation of budget surplusses by the central government, known as the "Julius Tower" policy. 
government, and its impact was generally anti-cyclical, the effect of budget changes by the central government was an even larger anticyclical force. Partly, this was due to the fortuitous development of expenditures associated with rearmament, especially during 1958 , but the automatic functioning of the tax system was a strong stabilizing influence also.

Social security was a relatively unimportant element in the calculation of budget effects. Benefits somewhat exceeded contributions, thus requiring the transfers from the central government already mentioned, and added on average 0.1 per cent to GNP. The automatic stabilizing effect of the social security system was noticeable, and provided a strong upward push during the 1958 recession while it was a dampening factor in years of rapid growth of demand. Discretionary changes were even more important, but they were not well coordinated with stabilization requirements. For example, contribution rates were increased during the 1958 recession, and subsequently they were reduced while benefits were increased during 1964 at a time when the economy was generally believed to have been somewhat overheated, and dampening rather than expansionary policies would have been more appropriate.

\section{Evaluating Economic Stability and Balanced Growth}

The objectives of economic policy are everywhere numerous, and the instruments used to achieve them are even more so $^{1}$; nevertheless, four goals predominate, although others may temporarily replace some of them from time to time, or one objective may completely dominate for a short while to the detriment of maintaining an appropriate balance among the others. These four are of primary concern to all governments: growth; employment, prices, and balance of payments. Changing budgetary expenditures and tax rates are only some of the means by which economic policies influence the economy generally and the level of demand, particularly its composition. Monetary policies, direct controls, and changes in the institutional framework are other important categories of instruments at the disposal of governments in their attempt to achieve an appropriate balance among the desired objectives. It was not the purpose of the Hansen study or of this paper to evaluate the total complex of all government policies. Rather the subject is more limited; given whatever influence other economic policies have had on the level of domestic demand, what have been the total effects of budget changes - automatic and discretionary combined - in helping or hindering the economy to achieve economic stability and growth?

Two approaches are possible: (I) a detailed examination of the conjunctural scene for the review period with a comparison and evaluation of

${ }^{1}$ One study of economic policy (E. S. Kirschen, et. al., Economic Policy in Our Time, Vol. I: General Theory, Amsterdam, 1964, pp. 148sq.) lists eight major conjunctural and structural objectives and four minor targets; and it enumerates no fewer than sixty-five instruments available to achieve them. 
the effects of budgetary policies as they relate to the desired objectives, to the extent that these are in fact known; this was generally the method adopted in the Hansen study; or (2) taking as an approximation that there did exist a known path of development which if consistently followed would have been optimum with respect to the economic goals desired. The second approach is employed in this study.

Countries differ considerably as to the degree that they accept and seek to use budgetary policies as an instrument for managing demand. Therefore, to evaluate how effective policies were in helping to achieve balanced growth and stability can be misleading if it is interpreted as an evaluation of the desired objectives of government policies. This is particularly true for Germany because throughout most of the period under review there was very little explicit attempt to use the budget to achieve or maintain full employment. The prevailing budget philosophy was mainly concerned with balancing the budget. Underlying this desire was the belief that balanced budgets meant financial respectability which was necessary in order to maintain price stability. Germany was probably more concerned about the possibility of rising prices than any other country among those in the Hansen study, although both Belgium and the United States also placed a high priority on price stability. Undoubtedly, this was related to the memory of the hyper-inflation which followed World War I, and the similar, albeit diminished, situation in the years immediately following World War II. Strictly speaking it was not until the enactment of the Stabilization Law in 1967 that official policy changed to the recognition that the systematic coordination of budget policies with the economy's conjunctural needs was required ${ }^{1}$. It should be mentioned, however, that this shift in philosophy had begun earlier, and was partly responsible for the creation in 1963 of an independent Council of Economic Experts who have since been charged with presenting an annual analysis of the prospective economic situation and the role of government's budget policies in molding the course of future events. The new Stabilization Law requires the federal government to advise the Parliament on the Council's report, and recommend measures that would be appropriate to achieve the desired economic targets.

It needs to be recalled that the de facto impact of budget policies was generally not very large, and - as will be discussed later in this section the actual course of events was not very greatly influenced by government policies. It must be equally stressed that the actual development of the German economy during the late 1950's and early 1960's did not deviate

${ }^{1}$ It should be recalled, however, that German economists during the early thirties were among the first, along with the Swedish, to recognize that government budget policies could, and properly should, perform a positive role in achieving full employment. Under the influence of Dr. Hjalmar Schacht, the Third Reich purposely used deficit financing to reduce unemployment. This experience had apparently no influence on economic considerations after World War II, undoubtedly because of the very different institutional framework of the two periods. See Hansen (op. cit., p. 228) for further comments. 
very much from what would have been the optimum path of development, if such a course could be agreed upon. Economic growth was extraordinary throughout the period, prices were relatively as stable or more so than in other European countries, and the balance of payments could hardly have been more favorable. Therefore, the following evaluation could be said to be artificial in the sense that achieving balanced growth and stability did not receive high priority, but these objectives were generally attained anyway without being much influenced by budgetary policies.

The following appraisal of the effects of budget changes uses as the criteria of optimum performance the degree to which their impact helped or hindered the German economy to achieve its full employment potential. The concept of "potential GNP" was introduced in President Kennedy's first Economic Report to the Congress of the United States ${ }^{1}$. It was designed to highlight how far the actual performance since 1955 had fallen short of the full economic potential of the United States, and to illustrate why special government policies were required to achieve a high level of employment. Undeniably the need for generally more expansive budget policies was real because after 1955 the unemployment rate continually exceeded 4 per cent and surpassed 7 per cent during the 1958 and 1961 recessions. By the standards of most European countries these rates would be totally unacceptable, but the United States is relatively more concerned with rising prices than many countries, although not as much due to the need to remain competitive in the international markets - although since 1965 this too has become an increasingly more important consideration - as in response to popular demand: Americans like Germans apparently abhor rising prices per se, relative or not. It must be noted, however, that frictional and structural unemployment problems seem to be greater in the United States than in other Western countries which makes it highly questionable whether without major institutional changes that country could reduce unemployment to the I per cent or less which has prevailed for many years in several European countries without their having run into problems of basic disequilibrium. Be that as it may, unemployment was excessively and unnecessarily high in the United States after 1955. After considerable congressional and public debate a series of exceptional tax reduction laws were passed which substantially reduced direct taxes on both households and corporations, and which would eventually eliminate most Federal indirect taxes in the United States. The impact of these discretionary measures during 1964 and 1965 finally helped boost the American economy back to a high level of employment (i. e., about 4 per cent), but during the eleven years which had passed since it had last operated at what for the United States can be considered its full economic potential, the accumulated gap between actual and potential GNP amounted to nearly so per cent of a typical year's potential full employment output (measured at constant 1958 prices).

${ }^{1}$ United States, Economic Report of the President 1962, Washington, D.C., 1962, p. 52. 
No similar estimates of potential output have been officially published for Germany, but Professor Lundberg ${ }^{1}$ in a recent study of the problems of economic instability faced by the major countries of Western Europe and North America in the postwar period discusses the problem and provides the required estimates. He defines potential or full employment output to be the combination of an unemployment rate of 2 per cent, which he considers to be "the minimum feasible unemployment rate to be applied uniformly for calculating the potential or full-employment labor force"2, and the long-run trend of labor productivity. His estimates for Germany imply that the annual rate of growth of potential GNP was somewhat higher up to 1956-57 when the labor force was still expanding rapidly, but afterwards the growth of potential output declined to an average of about $5^{1 / 2}$ per cent with only small annual deviations due to changes in the growth of the labor force and labor productivity ${ }^{3}$.

Figure I compares Professor Lundberg's estimates of potential output with the actual growth of GNP from I955 to 1965 (at constant 1958 prices). These estimates seem to be quite reasonable up to 1959 with regard to the gap between potential and actual GNP. For example, the short fall of GNP below its full employment potential was about 2 per cent in 1955 when unemployment was about 4 per cent, and the gap was negligible in 1959 when unemployment had declined to 2 per cent which is Professor Lundberg's criterion of a fully employed economy. Whether or not actual GNP generally exceeded potential output by as much as 2 or 3 per cent afterward is an implication that will be discussed later, but for the present these estimates of potential output are accepted as the basis for which the preliminary evaluation of the effects of budgetary policies can begin.

Part II of this study explained how the total effects of budget changes for the general government sector contributed an average upwards push of 0.4 per cent of GNP annually (see Table I). Thus, actual GNP as shown in Figure $I$ includes the impact of the discretionary as well as the automatic effects of budget changes. It is relevant to inquire about the extent to which their combined or total effects helped or hindered the achievement of economic stability and balanced growth. This can be assessed by constructing a hypothetical series of GNP as it would have developed without the total effects of annual budget changes by subtracting them from actual GNP for each year. This hypothetical series is called the "pure cycle," because it

1 Erik Lundberg, Instability and Economic Growth, Studies in Comparative Economics, 8., New Haven and London, 1968.

Ibid., p. 99.

3 The rate of growth of the labor force was about $\mathrm{I}^{1} / 2$ per cent annually until $1956-57$, after which it declined until the Berlin Crisis of 1962, and then dropped sharply to about $0.3-0.4$ per cent including the eventual supplement provided by the migration of workers from Southern Europe and Turkey (Hansen, op. cit., p. $21_{3}$, and Organization for Economic Co-operation and Development, Labour Force Statistics, IV: 1956-1966, OECD Publications, No. 23,613, Paris, 1966, p. 85). 
Measuring the Effects of German Budget Policies, r955-65

Figure I - Gross National Product : Actual and Potential, 1955-65

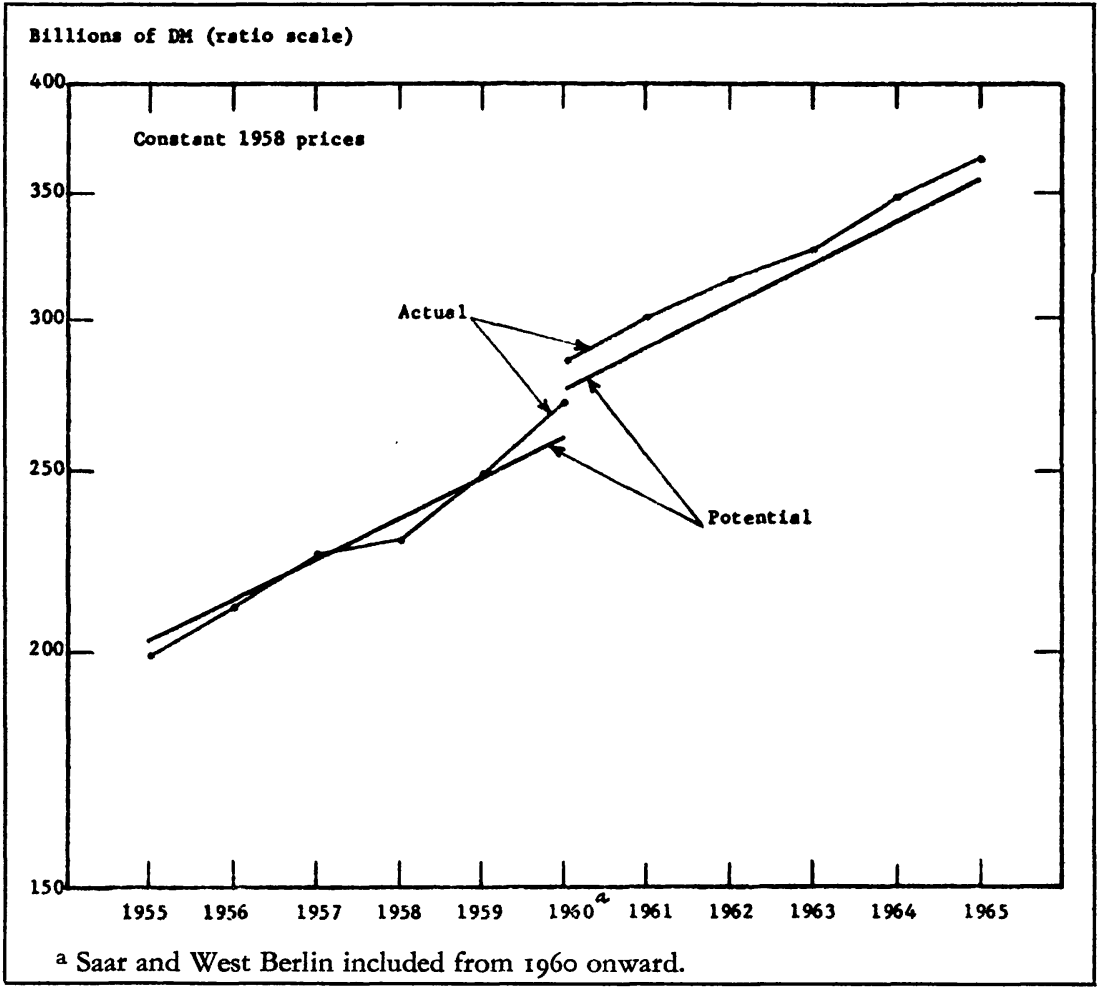

attempts to estimate what the GNP-growth rate would have been if there had been no change in the budget, i. e., if neither expenditures nor revenues had changed from one year to the next. The pure cycle is useful for comparison with both actual and potential GNP in order to assess the degree to which budget policies were a positive or negative contribution to stability and growth. The pure cycle attempts to eliminate only the effects of budget changes, and still includes the effects of other government policies (monetary and direct controls) as well as autonomous forces (e. g., private investment and exports) after allowing for endogenous mechanisms (e. g., leakages through private savings and imports) ${ }^{1}$. Hence, the pure cycle is not so pure, but it is nevertheless a useful analytical tool.

Figure 2 shows the actual GNP (solid line) and the pure cyle (dashed line), both expressed as deviations from potential output which is shown for convenience as a horizontal line. The vertical difference between the actual GNP and the pure cycle is equivalent to the total effects of budget changes

${ }^{1}$ See the Appendix for further details. 
Figure $2-$ Deviations of Actual GNP and the Pure Cycle from Potential Output, $1955-65$

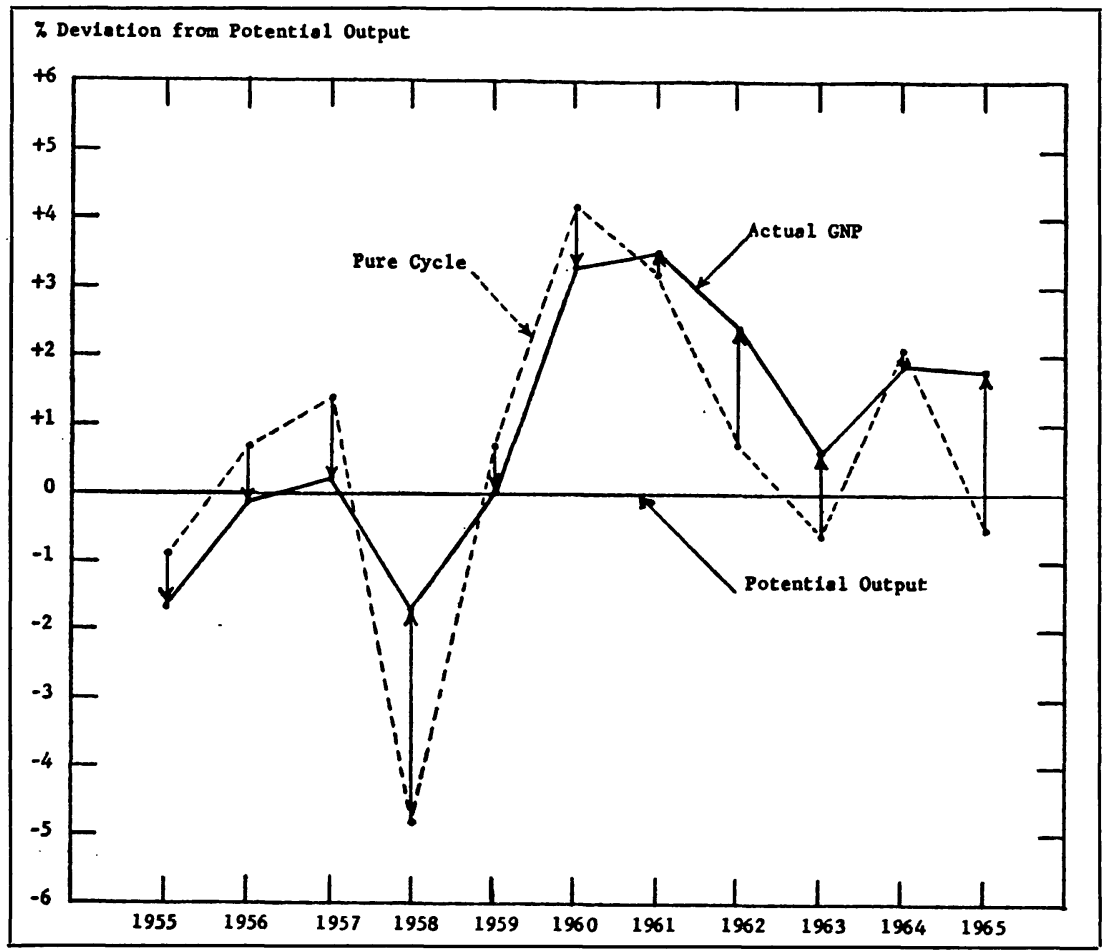

for general government as shown in Table I. The arrows indicate the direction of the total effects and point from the pure cycle to the actual GNP. Arrows which point towards potential GNP indicate budget effects which helped achieve the full employment potential, and those pointing away indicate years when the effects of budget changes were destabilizing.

The following brief description of actual developments from 1955 through 1965 will be helpful in evaluating the impact of German budgetary policies. In I955 the economy was still operating below its full potential, but the gap had been steadily diminishing due to the phenomenal growth of output. During 1956 and 1957 virtual full employment was finally achieved, but in 1958 the German economy suffered some - but not excessively from the recession which affected all Western countries. During 1959 full employment wass quickly regained, and from 1960 onward the economy consistently functioned at an excessively high level of demand which was, however, most pronounced during $1960-62$.

It is fairly obvious from Figure 2 that these actual developments were not greatly affected by the impact of budget changes. Observe in Figure 2 
how small is the difference between the pure cycle and the actual GNP, and compare also these curves with the potential output. The year 1958 is, however, an exception as the combination of increased spending and the automatic reduction of tax revenue were important factors which eliminated much of the potential recession, and after 1961 the budget generally added $\mathrm{I}-\mathrm{I}_{2}^{1}$ per cent to the GNP-growth rate. Though the budget was a minor factor, the extent to which it helped or hindered the achievement of economic stability and balanced growth can be evaluated, and the relevant relationships are summarized in Table 2.

The accumulated divergence between the pure cycle and the potential GNP from 1955 through 1965 amounted to 19.8 per cent. The potential stabilization was about twice as great when demand was excessive as when the economy was functioning at less than full capacity. There was not any noticeable difference in the tendency of either the stabilizing or the destabilizing effects to be relatively more important depending on whether the economy was over or under fully employed. While the (gross) stabilizing effects amount to 7.9 per cent, the destabilizing effects were almost as large and amounted to 5.3 per cent, so that the net stabilizing impact of budget changes was reduced to only 2.6 per cent. Thus, on a net basis the budgetary effects were a positive, albeit small, contribution which reduced the amount of potential effects needed to achieve economic stability and balanced growth by 13. I per cent.

Table 2 - Total Effects and Economic Stabilization, 1955-65 (expressed as a percentage of potential GNP)

\begin{tabular}{|c|c|c|}
\hline & \multicolumn{2}{|c|}{ Per cent } \\
\hline 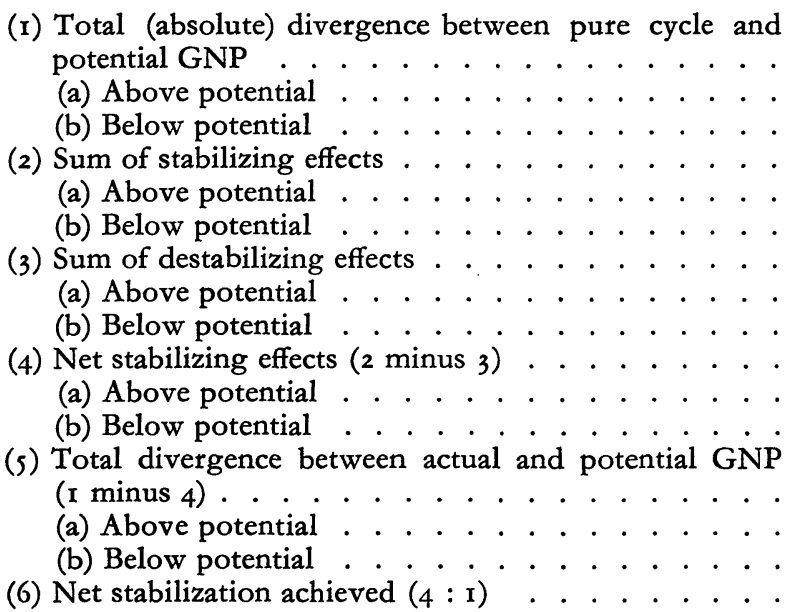 & $\begin{array}{r}\text { I } 3.0 \\
6.8 \\
\\
3.7 \\
4.2 \\
\\
2.1 \\
3.2 \\
\\
1.6 \\
1.0 \\
\\
\\
\text { II } 1.4 \\
5.8\end{array}$ & $5 \cdot 3$ \\
\hline
\end{tabular}


Table 3 - Potential Stabilization and Acbievement, 1955-65

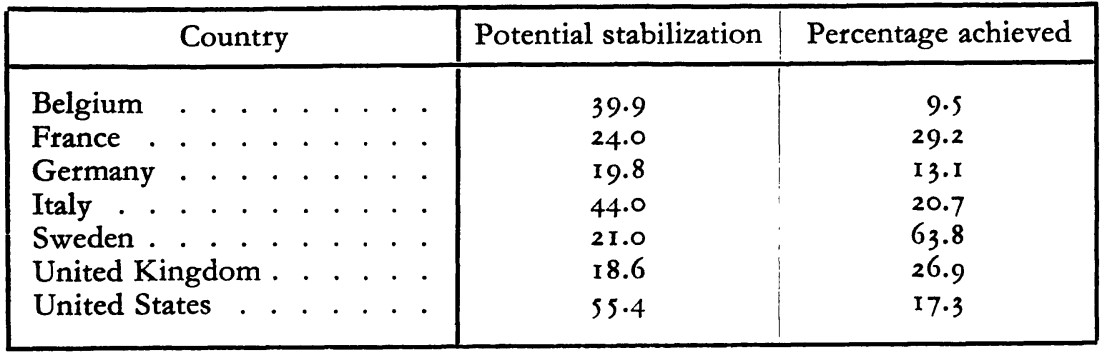

Using similar methods and criteria, the budgetary performance for all seven countries in the Hansen study are shown in Table 3, and provide a basis for comparing the other countries with Germany. The net effect of budget changes in every country was more stabilizing than not, but the differences between countries was substantial. Potential stabilization was roughly comparable at least in four countries: France, Germany, Sweden, and the United Kingdom. The percentage of achieved stabilization, however, differed noticeably among these countries. Sweden accomplished a remarkable amount which far exceeded that of any other country, a testimony to its very active budgetary policies where the philosophy of government intervention goes back to the 1930's. The effects of German budget changes did little to reduce potential stabilization, while in France and in the United Kingdom the effects were somewhat larger. Belgium and Italy had nearly twice as much potential stabilization - in each case associated with a high level of unemployment throughout most of the period studied - but whereas the budget policies in Italy were a positive contribution to the achievement of that country's full employment potential, in Belgium the impact of budget changes was relatively smaller than for any other country. The United States had the most potential stabilization and also the most unemployment, but budget policies contributed only moderately to its achievement.

At this point some further discussion is required about the pure cycle which was defined as the actual GNP-growth rate minus the total effects of general government. The analysis, thus far, has been on the impact of budgetary changes by the general government, and potential stabilization was defined relative to this concept. Many European countries have highly centralized systems where the central government has a decisive influence over the budgetary affairs of both the state-local sector and the social security system; Belgium, France, Italy, and the United Kingdom are typical examples. Clearly under these circumstances the appropriate level of analysis should include all government sectors, hence the general government. The United States, however, is a country where its central government has had only negligible influence over the state-local sector; what influence it has had has been limited to its ability to vary transfers to state-local governments 
which have not been traditionally very important, and via its monetary policies which affect the ease with which state-local governments can borro w in the open market. Clearly, for the United States the analysis and consequently the pure cycle need to be confined to the budget impact of the federal government only.

Germany is an intermediate case where it is difficult to decide which level of aggregation is the most appropriate for the appraisal of the effects of budget policies. Taxes, generally, require approval at the Bund level, hence the federal government has considerable control over the revenue of state-local government, although by law it must share a portion of certain taxes with the Länder which in turn have to share with the Gemeinden. The federal government also controls transfers which have not been traditionally large relative to the other revenue sources of state-local government, but they have been growing rapidly. In principle, the Länder and Gemeinden have complete freedom over their expenditures which are large relative to those of the federal government for which the Constitution has limited its field of activities. State-local government may also borrow freely on the open market, although their indebtedness to the Central Bank is strictly limited, as it is for the federal government also. In sum, the relationship between the central and the state-local government sector is not a simple one, and consequently it is not easy to decide whether the evaluation of budget policies should be made inclusive or exclusive of the state-local sector. Therefore, it is best to provide both by indicating to what extent the foregoing evaluation requires modification if the budget effects of the central government are considered alone.

If the pure cycle is redefined so as to be constructed by subtracting from the actual GNP the total effects of only the central government, then the following changes result and can be compared with the data of Table 2. Potential stabilization, the accumulated sum of the (absolute) differences between the "new" pure cycle and the potential GNP increases from 19.8 per cent of GNP to 23.4 per cent. The major reason for the increase is that the total effects of state-local budget changes became more expansive after $196 \mathrm{I}$ so that a "new" pure cycle which includes their impact is lifted higher than the one shown in Figure 2, and consequently the amount of potential stabilization is greater. Using the criterion that total effects which diminish the gap between this "new" pure cycle and potential output are stabilizing, while the contrary is defined to be destabilizing, then the amount of (gross) stabilizing effects increases from 7.9 per cent for general government to 8.8 per cent for central government alone. More important is the fact that on a similar basis, the amount of destabilizing effects is reduced from 5.3 per cent to 2.6 per cent, again primarily because due to the destabilizing effects of general government which result from the increased expansiveness of state-local budgets after 1961 when the economy was operating at an excessively high level of demand. The combined result is that the net stabilizing effects increases to 6.2 per cent for central government alone as compared 
with 2.6 per cent for general government, and the percentage of achieved stabilization increases from 13.1 to 26 per cent.

As suggested previously, these are two ways of looking at the effects of budget policies, and neither is necessarily more relevant than the other - at least for the period actually studied. The fact that the state-local government budgets tended to be overly expansive and hence destabilizing after 196I points to the need for better coordination of budgetary policies among the different sectors of government. The new Stabilization Law states the principle that the Bund and Länder (and by extension the Gemeinden also) should jointly take into account the budgetary policies which are required for economic equilibrium. Furthermore, the Law authorizes the federal government to require both the Bund and the Länder to make special deposits from their revenues with the Bundesbank, if the dampening of demand is deemed necessary. These "conjunctural accounts" can later be used to finance budget deficits if more expansive policies are thought desirable, and if ordinary revenue and borrowing would not be sufficient to meet the national expenditure objectives. It is worth noting, however, that these "conjunctural accounts" cannot become negative, so that the possibilities of fighting a potentially inflationary situation are greater than the freedom to combat inadequate demand $-\mathrm{a}$ realistic limitation in light of the probable situations that the German economy is likely to face in the years ahead.

Before ending this section it is necessary to discuss the other economic objectives - price stability and the balance of payments equilibrium - in relationship to maintaining a fully employed economy, and the concept of potential output itself. The previous analysis suggests that budget policies should have been generally more expansive up to I959, and afterward they should have generally dampened demand rather than adding to it. This view is open to question, however, because the evaluation must be weighed against price and balance of payments developments. Prices rose relatively strongly up to 1958 , and were a considerable preoccupation of the government authorities. Also more expansive policies during this period would have diminished the balance of payments surplusses which were needed eventually to procure from abroad the materials required for German rearmament. If potential output is defined with respect to a level of 2 per cent unemployment, clearly after 1959 the German economy functioned at an excessively high level of demand which was more than previously due to the expansive effects of government budget changes. The degree of excessive demand is, however, difficult to judge precisely. Although unemployment fell well below one per cent after 1960, prices rose no more rapidly than in most other European countries, so that exports remained competitive. This along with other factors helped produce overall balance of payments surplusses so that there was a very substantial increase in the official holding of gold and foreign reserves from 1955 to 1965 , even after the large payments for rearmament, and enough so that Germany's reserves far exceeded those of any other Western country, except the United States. Partly, this pheno- 
menal increase must be attributed to high interest rates which must be attributed to Germany's generally tight monetary policies during this period. It might be argued that Germany's accumulation of international reserves has been excessive and detrimental to general financial stability in Europe. If this view is accepted, then somewhat less expansive budgetary policies after 1959-60 accompanied by easier monetary policies would have been capable of maintaining a fully employed economy without encouraging the inflow of capital which added to the large balance of payments surplusses which have been associated with unfavorable reactions elsewhere. This points to an area where economic policies could be improved, but which is a subject outside the reference of this study: the better coordination of budgetary and monetary policies.

\section{Summary and Conclusion}

The development of the German economy during the years from inss through 1965 was remarkable and clearly outdistanced the achievement of most other European countries. Generally, however, this was very little influenced by the budgetary policies which only occasionally modified to a noticeable degree the course of events. On balance the net impact of budget changes was a positive factor in achieving economic stability and balanced growth, but it must be noted that the amount of potential stabilization was not particularly large, and neither was the amount of stabilization achieved. Some improvement could have been obtained if the government budgets had been somewhat more expansive in the years before full employment was attained, and somewhat less expansive afterward. Further improvement toward achieving even more balanced growth would have resulted if monetary policies had been better coordinated with budget policies.

Until the passing of the Stabilization Law in 1967 budgetary policies were restrained by a preoccupation with balancing the budget, a philosophy which was reinforced by the limitation on borrowing from the central bank. The coordination of federal with state-local government budget policies has been seriously deficient, and a source of some instability. With the introduction of the Stabilization Law, the possibility of using the budget more actively as a tool of demand management has been created, and the special provisions for the modification of Bund, Länder and Gemeinden budget policies to meet the requirements of national objectives is henceforth possible. Only the future will show how well these new opportunities for improved policies can be realized.

\section{Appendix}

The basic methods used to estimate the impact of budget changes can be illustrated by reference to a very simple Keynesian model, where $Y$ is GNP, I is private investment, $C$ is private consumption, $G$ is government purchases of goods and services, $T$ is tax revenue, $\alpha$ is the marginal propensity to consume out of disposable income and $t$ is the marginal tax rate: 
(I) $\begin{aligned} & \mathrm{Y}=\mathrm{I}+\mathrm{C}+\mathrm{G} \\ & \mathrm{C}=\alpha(\mathrm{Y}-\mathrm{T}) \\ & \mathrm{T}=\mathrm{tY}\end{aligned}$

Changes in $\mathrm{Y}$ can be expressed by differentiating ( $\mathrm{I}$ ) which gives two equally good "reduced form" equations, where d indicates change (i.e., $\mathrm{Ydt}=$ change in tax revenue due to a discretionary change in the tax rate):

(2) $\quad \mathrm{dY}=\frac{1}{1-\alpha(1-t)}(\mathrm{dI}+\mathrm{dG}-\alpha \mathrm{Ydt})$

or

(3) $\quad \mathrm{dY}=\frac{1}{1-\alpha}(\mathrm{dI}+\mathrm{dG}-\alpha \mathrm{dT})$

Either (2) or (3) is equally good for explaining changes in Y, but (3) requires knowing only the amount of total change in taxes (dT) while (2) requires knowing the amount of discretionary change in taxes ( $\mathrm{Ydt}$ ).

The discretionary effects of budget changes, $E_{\text {discr., }}$ are defined as the difference between the actual change in $\mathrm{Y}$ and the change which would have occurred if there had been no discretionary change in the budget from one year to the next (i.e., if dG and Ydt are both equal to zero), but allowing for leakages into private savings and automatic tax changes; then from (2):

(4) $\begin{aligned} \mathrm{E}_{\text {discr. }} & =\mathrm{dY}-\frac{1}{1-\alpha(1-\mathrm{t})} \mathrm{dI} \\ & =\frac{1}{1-\alpha(1-\mathrm{t})}(\mathrm{dG}-\alpha \mathrm{Ydt})\end{aligned}$

The total effects of budget changes, $E_{\text {total }}$, are defined as the difference between the actual change in $\mathrm{Y}$ and the change which would have occurred if no budget change at all had occurred, which means that the marginal rate of taxes would have to be zero as in (3):

(5) $\quad E_{\text {total }}=d Y-\frac{1}{1-\alpha} d I$

$$
=\frac{1}{1-\alpha}(\mathrm{dG}-\alpha \mathrm{d} \mathrm{T})
$$


An explicit expression for the automatic effects of budget changes, $E_{\text {auto., }}$ can be derived, but as the total effects of budget changes are the sum of both automatic and discretionary changes, it is easier to define them simply as the difference between the total and the discretionary effects:

$$
\mathrm{E}_{\text {auto. }}=\mathrm{E}_{\text {total }}-\mathrm{E}_{\text {discr. }}
$$

The definitions and methods actually employed to estimate the impact of budget changes are based on the previous contributions of Brown ${ }^{1}$, Hansen $^{2}$, Lindbäck ${ }^{3}$, and Musgrave ${ }^{4}$. Compared with the large econometric models which have been developed for some countries, the one in the Hansen study is admittedly primitive, partly because of the desire to use a common analysis for each of the seven countries. For the same reason year-to-year changes are used and no lags are introduced ${ }^{5}$. The model assumes that private investment, exports, and prices (except those caused by discretionary changes in indirect tax rates) are exogenously determined. Imports are endogenous and for some countries represent the principal leakage of the potential budget effects. Government expenditures distinguish between volume and price changes, the latter necessitated by the differentiation of direct from indirect taxes.

The two reduced form equations, comparable to those of the simple Keynesian model above, for estimating the budget effects are:

$$
\begin{aligned}
& \mathrm{E}_{\text {total }}=\frac{1}{1-\alpha(1-\mu)}\left\{\begin{array}{l}
+\left(\mathrm{dg}^{\mathrm{d}}+\mathrm{dl}\right) \\
+\left(\operatorname{dg}_{\mathrm{g}}+\mathrm{ddw}\right)[\alpha(1-\mu)] \\
-\mathrm{dT}_{\mathrm{i}}(1-\mu) \\
-\mathrm{dT}_{\mathrm{d}} \alpha(1-\mu)
\end{array}\right. \\
& \mathrm{E}_{\text {discr. }}=\frac{1}{1+\mathrm{t}_{\mathrm{i}}-\alpha(1-\mu)\left(1-\mathrm{t}_{\mathrm{d}}\right)}\left\{\begin{array}{l}
+\left(\mathrm{dg}^{\mathrm{d}}+\mathrm{dl}\right)\left(1+\mathrm{T}_{\mathrm{i}}\right) \\
-\mathrm{cdt}_{\mathrm{i}}(1-\mu) \\
-\mathrm{ydt}_{\mathrm{d}} \alpha(1-\mu)
\end{array}\right.
\end{aligned}
$$

${ }^{1}$ E. Cary Brown, "Fiscal Policy in the Thirties: A Reappraisal", The American Economic Review, Vol. XLVI, Menasha, Wisc., 1956, pp. 857 sqq.

¿ Bent Hansen, "Statsbudgetens verkningar", Ekonomisk Tidskrift, Årg. LXI, Uppsala, 1959, pp. I 28sqq.

${ }^{3}$ Assar Lindbäck, Statsbudgetens verkningar pả konjunkturutvecklingen, Undersökning utarb. inom finansdepartementets nationalbudgetkansli, Statens Offentliga Utredningar 1956: 48, Stockholm, 1956.

4R. A. Musgrave, "On Measuring Fiscal Performance", The Review of Economics and Statistics, Vol. XIVI, Cambridge, Mass., 1964, pp. 213sqq.

- A review of several big models suggests that three quarter or more of the budget effects generally occur during the first year, so the absence of explicit lags is not critical; see Hansen (Fiscal Policy, op. cit., pp. 20sqq.) for a detailed discussion of this subject. 
Equation (7) estimates the total effects of budget changes, specifically allowing for the following factors:

(a) Changes in the volume of government purchases of goods ( $\mathrm{dg}^{\mathrm{d}}$ ) and services (dl) are distinguished from their respective price changes $(\mathrm{dgp} g+\mathrm{ldw})$.

(b) Only domestic purchases are included; direct government expenditures abroad were an important component of annual changes for some countries during the period studied (military payments in particular) and are excluded because they do not affect domestic demand.

(c) Changes in indirect taxes on households $\left(\mathrm{dT}_{\mathbf{i}}\right)$.

(d) Changes in direct taxes on households $\left(\mathrm{dT}_{\mathrm{d}}\right)$.

(e) Leakages via the marginal propensity to consume $(\alpha)$ and via the marginal propensity to import $(\mu)$. The model contains no explicit corporate business sector; consequently $\alpha$ measures the ratio between changes in personal consumption and changes in total private income minus only direct taxes on households. This implies an assumption of a constant relationship of gross corporate profits to income which is unaffected by changes in corporate income taxes.

(f) The weighting allows for changes in domestic expenditures $\left(\mathrm{dg}^{\mathrm{d}}+\mathrm{dl}\right)$ to have their full multiplier effects (i.e., direct plus indirect), while the other items have only indirect or second-round-and-after effects (e.g., increased wages to government employees or reduced household taxes both raise private income, some of which is saved and only afterwards begins to effect domestic demand).

Equation (8) estimates the discretionary effects of budget changes, specifically allowing for the following factors:

(a) Changes in the volume of government domestic purchases of goods and services $\left(\mathrm{dg}^{\mathrm{d}}+\mathrm{dl}\right)$.

(b) Discretionary changes in the value of indirect taxes on households $\left(\mathrm{cdt}_{\mathbf{i}}\right)$.

(c) Discretionary changes in the value of direct taxes on households $\left(\mathrm{ydt}_{\mathrm{d}}\right)$.

(d) Marginal rate of indirect $\left(t_{i}\right)$ and direct $\left(t_{d}\right)$ taxes on households. The above suggest several important implications:

(a) All changes in the volume of government domestic purchases are counted as discretionary, whereas in reality some expenditures are tied to legislated norms and programs (e.g., education standards in some countries).

(b) All budget effects from changes in prices and salary rates paid by the government are considered to be automatic, although govern- 
ments do have varying degrees of control over some prices (e.g., goods and services produced by public enterprises, and commodity price support programs) and when and by how much government wages are increased.

(c) Neither tax changes nor price and wage changes are deflated. This is because the model assumed that prices, before indirect taxes, are exogenously determined and are only influenced by discretionary changes in direct taxes. Other authors sometimes deflated both ${ }^{1}$, but to do so would have introduced an inconsistency between equations (7) and (8), given the model's assumption about price determination.

(d) The weighting system implies that a unit of discretionary change in government purchases will have a greater effect than a unit change in taxes, and among the latter the discretionary effects of a unit change in indirect taxes has a larger effect than a similar change in direct taxes. These results are well known from the literature about the "balanced budget multiplier" and are generally consistent with the implicit multipliers of the "big models."

$A$ note on the statistical methods: Most data were derived from adjustments to the national accounts statistics published by the $\mathrm{OECD}^{2}$. Individual countries furnished supplementary information on government imports and the estimated amount of discretionary changes in direct $\left(\mathrm{ydt}_{\mathrm{d}}\right)$ and indirect $\left(\mathrm{cdt}_{\mathrm{i}}\right)$ taxes on households (i.e., the difference between the actual and what would have occurred in the absence of any change in the tax rates). The estimates of the budget effects obtained from equations (7) and (8) are expressed in terms of the previous year's prices. In order to compare the effects of one year with another, they were normalized by expressing them as a percentage of the previous year's GNP. The estimates of the various budget effects given in Table I were obtained in this manner. For the data used in Figure 2, however, it was necessary to use the appropriate GNP deflators in order to express all the budget effects in constant 1958 prices.

Equations (7) and (8) used to estimate total and discretionary effects of budget changes imply multipliers which depend on various leakage coefficients; these are given in Table A-r. The marginal rates of taxation refer to general government not central government alone. If the consumption coefficient seems small, it must be remembered that $\alpha$ is the ratio between changes in personal consumption and changes in total private income minus only direct taxes. Using this definition, Germany's marginal propensity to consume ( 70 per cent) is at the low end of the range for the seven countries where similar coefficients varied from 70 to 80 per cent. The assumption that marginal propensity to consume was constant seems to be quite reasonable before 1960 and after 1962 , but from 1960 to 1962 both household

1 For example, see Brown, op. cit.

2 For the methods and the definitions see: Organization for Economic Co-operation and Development, $A$ Standard System of National Accounts, 1958 Ed., Paris, 1964. 
Wayne W. Snyder, Measuring the Effects of German Budget Policies, I955-65

Table A-I - Leakage Coefficients and Multipliers

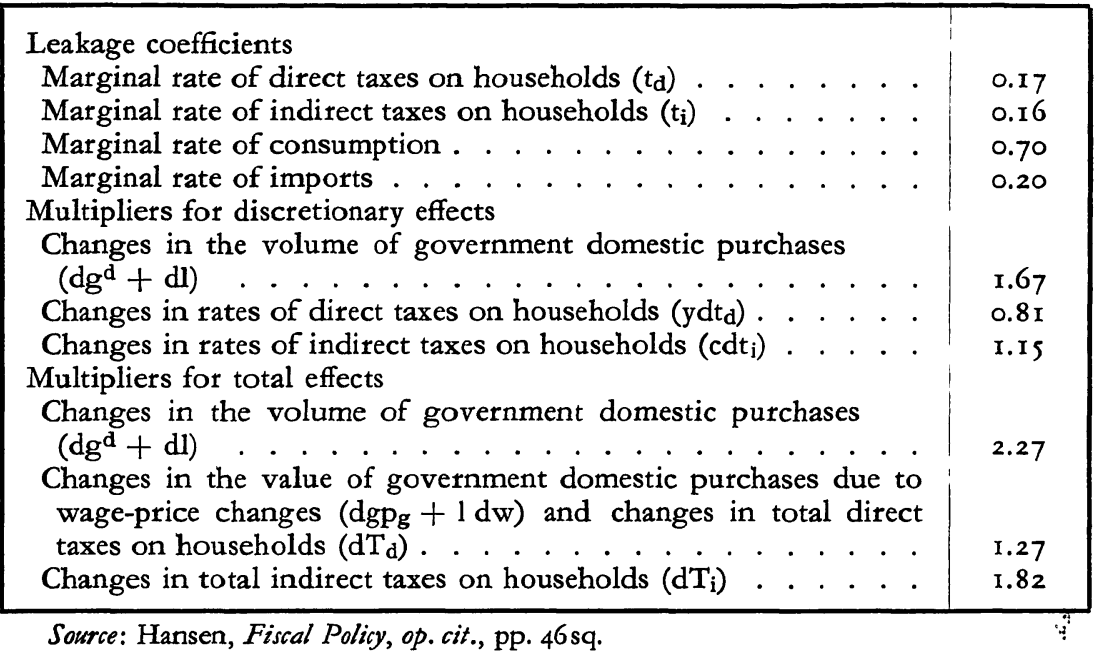

and corporate savings stagnated as consumption and investment surged upward, contributing to the full and over full employment which existed from 1960 onward. Germany's marginal propensity to import (20 per cent:) remained rather stable throughout the period, and was also fairly low among the six European countries where the coefficients range up to so per cent (Belgium), but it is still considerably higher than for the United States ( $s$ per cent). While the rate of total taxes to GNP varies some between countries, there is more variation among countries for each category of tax: direct or indirect. Germany's marginal rate of direct taxes ( 17 per cent) is about twice as large as for its Common Market partners (i.e., Belgium, France, and Italy), and comparable with the rates in the United Kingdom and the United States, but less than Sweden's 30 per cent. Germany's marginal rate of indirect taxes ( 16 per cent) is about average among the seven countries, where the rates varied between ro and 20 per cent. The assumption that these marginal tax rates remained constant throughout the period seems to have been reasonable for Germany. These leakage coefficients result in multipliers which are just about midway between the somewhat lower ones for Belgium, Sweden, and the United Kingdom, and the higher ones for the other three countries. 

